\title{
ANALISIS SISTEM KEMITRAAN DALAM PROGRAM IMUNISASI BERDASARKAN PERAN PERANGKAT DESA, BIDAN DESA, DAN MASYARAKAT
}

\section{PARTNERSHIPS SYSTEM ANALYSIS IN IMMUNIZATION PROGRAM BASED ON THE ROLE OF FORCES THE VILLAGE, MIDWIFE VILLAGE, AND SOCIETY}

Aqsha Yuldan Arifada, Thinni Nurul Rochmah

Fakultas Kesehatan Masyarakat, Universitas Airlangga, Surabaya

E-mail: rajendra_aqsha@yahoo.co.id

\begin{abstract}
Sumenep regency as the most eastern districts in the region Madura have not been able to meet the target of Universal Child Immunization (UCI) coverage in accordance with the Minimum Service Standards (SPM) Indonesian government. Application of the village partnership system is expected to increase the scope of UCl in the village. This research is aimed to analyze the inputs, processes, and outputs the village partnership system is based on the role of village officials, village midwives, and society. This study uses observational descriptive with cross sectional design. Samples were collected using stratified random sampling method consist of the villages, midwives, and community groups. The result showed that the majority of village officials, midwives, and community groups unoptimal in partnership system in the village, so the need to improvements to the village partnership system is good an solid. There was no significant effect of the variables role of village officials and midwives to result UCl village coverage. On community variables, the process of partnership, and the result of partnership, there are several variables that have significant influence. Based on the survey result it can be concluded that the system of partnership in the area Puskesmas do not use the integrated partnership model, but using a network model of partnership.
\end{abstract}

Keywords: community development, immunization, partnership, Universal Child Immunization

\section{PENDAHULUAN}

Kesehatan sebagai salah satu unsur kesejahteraan masyarakat, perlu diwujudkan sesuai dengan strategi pembangunan kesehatan nasional untuk mewujudkan Indonesia Sehat 2015. Salah satu program pemerintah, sebagai upaya pembangunan kesehatan dengan memberikan prioritas utama pada upaya preventif (pencegahan) dan promotif (peningkatan pelayanan kesehatan). Salah satu program pemerintah yang mengarah pada upaya preventif dan promotif adalah program imunisasi sebagai upaya pengebalan terhadap penyakit menular.

Dalam menjalankan program imunisasi yang efektif dan efisien, perlu adanya dukungan baik dari Puskesmas selaku provider maupun dari masyarakat. Dalam kehidupan sehari-hari, istilah kemitraan lebih dikenal dengan istilah gotong royong yang diartikan melibatkan seluruh warga masyarakat. Kemitraan merupakan upaya yang melibatkan berbagai komponen, yaitu masyarakat, lembaga pemerintah dan lembaga non-pemerintah untuk bekerja sama dalam mencapai tujuan yang diinginkan sesuai dengan kesepakatan, prinsip, serta peran dari masing-masing pihak.

Kegiatan imunisasi sebagai salah satu prioritas utama dari Kementerian Kesehatan Republik Indonesia, dilaksanakan guna mewujudkan Millenium Development Goals (MDG's). Indonesia masih menjadi salah satu negara yang diprioritaskan oleh WHO dan UNICEF untuk mencapai target $100 \%$ desa UCI (Universal Child Immunization). Hal ini dikarenakan Indonesia masih masuk dalam peringkat keempat di dunia dengan jumlah anak yang tidak mendapatkan imunisasi DPT3 (Difteri, Polio, dan Tetanus). 
Kabupaten Sumenep, sebagai salah satu daerah yang wilayahnya berada di paling timur wilayah Madura termasuk yang belum memenuhi target cakupan desa UCl. Hingga tahun 2013, Kabupaten Sumenep memiliki 276 desa dari total 332 desa yang telah berstatus $\mathrm{UCl}$ atau sebesar 92,21\%. Puskesmas Pamolokan sebagai Puskesmas percontohan di Kabupaten Sumenep, terus mengalami penurunan dalam cakupan desa UCl hingga tahun 2013.

Salah satu upaya untuk meningkatkan cakupan desa $\mathrm{UCl}$ adalah melalui proses kemitraan antara Puskesmas selaku provider dan masyarakat. Puskesmas dapat terwakili dengan adanya bidan desa yang ditempatkan pada desa di wilayah kerja Puskesmas. Dalam menjalankan perannya sebagai motivator kesehatan, bidan desa diharapkan mampu menjalin kerjasama dengan perangkat desa, kader kesehatan, dan ibu bayi untuk menyukseskan program imunisasi di wilayahnya.

Tujuan dari penelitian ini adalah menganalisis sistem kemitraan desa pada seluruh desa di wilayah kerja Puskesmas Pamolokan, Kabupaten Sumenep dengan mengidentifikasi dimensi input, proses, dan output dari kemitraan di desa yang melibatkan perangkat desa, bidan desa, dan masyarakat. Manfaat dari hasil penelitian ini bagi Puskesmas adalah sebagai sarana untuk memperbaiki sistem kemitraan yang terjalin di masyarakat pada wilayah kerjanya.

\section{PUSTAKA}

Pusat Kesehatan Masyarakat (Puskesmas) merupakan sarana kesehatan yang melaksanakan pelayanan kesehatan secara paripurna kepada masyarakat. Berdasarkan Kepmenkes 128/MENKES/SK/II/2004 tentang Kebijakan Dasar Puskesmas, fungsi Puskesmas terbagi menjadi tiga poin utama yaitu: (1) Pusat penggerak pembangunan berwawasan kesehatan, (2) Pusat pemberdayaan masyarakat, (3) Pusat pelayanan kesehatan strata pertama yang meliputi pelayanan kesehatan perorangan, dan pelayanan kesehatan perorangan. Sebagai pelayanan strata pertama, selain memberikan pelayanan kesehatan perorangan, Puskesmas juga bertanggung jawab terhadap keberhasilan pembangunan kesehatan secara menyeluruh di wilayah kerjanya.

Keberhasilan Puskesmas tidak ditentukan berdasarkan banyaknya jumlah pasien yang berobat, melainkan berdasarkan Standar Pelayanan Minimal (SPM) yang telah dikeluarkan oleh Menteri Kesehatan RI. Dalam SPM Puskesmas telah diatur indikator serta target yang harus dicapai, misalnya $100 \%$ cakupan desa UCI, 95\% cakupan kunjungan ibu hamil K4, 80\% cakupan desa siaga aktif, dan beberapa indikator kesehatan lainnya.

Dengan mengangkat visi tercapainya kecamatan sehat secara menyeluruh demi terwujudnya program "Indonesia Sehat", Puskesmas mempunyai misi diantaranya menggerakkan pembangunan berwawasan kesehatan di wilayah kerjanya, serta mendorong kemandirian hidup sehat bagi keluarga dan masyarakat di wilayah kerjanya.

Sebagai Unit Pelaksana Teknis (UPT) kesehatan tingkat kecamatan, dalam melaksanakan tugas dan fungsinya, Puskesmas diharapkan dapat berkoordinasi dengan kantor kecamatan melalui 
musyawarah tingkat kecamatan atau pertemuan rutin lainnya. Oleh sebab itu, perlu adanya koordinasi lintas sektor di tingkat kecamatan baik dengan muspika ataupun kepala desa yang ada di bawahnya agar pembangunan kesehatan ini dapat didukung oleh stakeholder yang dapat memberikan pengaruh kepada masyarakat.

Sebagai penanggung jawab penyelenggaraan pembangunan kesehatan di wilayah kerjanya, Puskesmas tentu membutuhkan adanya partisipasi masyarakat untuk mewujudkan upaya kesehatan yang bersumberdaya masyarakat. Dalam Kepmenkes No. 128 tahun 2004, diungkapkan bahwa dukungan aktif masyarakat dapat diwujudkan melalui pembentukan Badan Penyantun Puskesmas (BPP) sebagai mitra kerja Puskesmas.

Menurut Kepmenkes Nomor 1059/MENKES/SK/IX/2004, imunisasi diartikan sebagai suatu cara untuk meningkatkan kekebalan seseorang secara aktif terhadap suatu penyakit. Kondisi tercapainya imunisasi dasar secara lengkap pada bayi, disebut dengan kondisi UCl (Universal Child Immunization). Imunisasi menggambarkan proses yang mengiduksi imunitas secara artificial dengan pemberian bahan antigenik seperti agen imunobiologis.

Di Indonesia, kegiatan imunisasi terbagi menjadi dua yaitu imunisasi rutin dan imunisasi tambahan. Imunisasi rutin merupakan kegiatan imunisasi yang secara rutin dan berkala dilakukan dalam jangka waktu yang telah terjadwal. Sasaran dari imunisasi rutin diberikan pada bayi, wanita usia subur, dan pada anak usia sekolah. Sedangkan imunisasi tambahan merupakan kegiatan imunisasi yang dilaksanakan karena adanya masalah yang ditemukan dalam kondisi adanya endemis baru.

Dalam pelaksanaannya, program imunisasi dituntut agar dapat terselenggara secara efektif dan efisien. Salah satu cara agar program imunisasi berjalan efektif dan efisien maka perlu adanya koordinasi baik lintas program ataupun lintas sektor. Koordinasi lintas program dilakukan dengan bekerjasama dengan program lain yang ada di Puskesmas, misalnya program Kesehatan Ibu dan Anak (KIA) atau program Upaya Kesehatan Sekolah (UKS). Koordinasi lintas sektor dilakukan untuk mengurangi terjadinya ketidak sepahaman lintas sektor, misalnya dengan Departemen Agama, Dinas Kesehatan, dan institusi pemerintah lainnya.

Dalam kamus besar bahasa Indonesia, dalam hal pekerjaan, mitra diartikan sebagai rekan kerja, sedangkan kemitraan diartikan sebagai hubungan kerjasama. Pada dasarnya, kemitraan adalah kerjasama tim dengan satu tujuan tertentu. Sehingga untuk menilai keberhasilan dari kemitraan dapat dilihat berdasarkan aktifnya peran serta provider, pihak yang terlibat, dan masyarakat secara keseluruhan. Proses kemitraan telah lama dijalankan oleh bangsa Indonesia dengan istilah gotong royong. Dapat disimpulkan, bahwa kemitraan merupakan bentuk kerjasama baik antar individu, antar kelompok, individu dengan kelompok, untuk mencapai tujuan tertentu dengan menanggung segala resiko maupun keuntungan secara bersama.

Menurut Notoatmodjo (2012) dan penelitian sebelumnya dari Pramudho (2009), kemitraan dipandang sebagai suatu kesisteman yang harus dijalankan secara harmonis dan koordinasi yang baik 
antar individu ataupun kelompok yang bermitra. Tiga prinsip dasar yang perlu dipahami oleh pihak yang akan bermitra adalah (1) Persamaan, (2) Keterbukaan, dan (3) Saling menguntungkan. Tiga prinsip ini harus dijalankan untuk mengurangi adanya kesenjangan yang terjadi dalam menjalankan proses kemitraan.

Seiring perkembangan teknologi, terdapat dua sistem kemitraan yang dapat diterapkan pada sektor kesehatan. Model jejaring kerja (Networking), merupakan model yang paling sederhana. Masingmasing anggota mitra telah mempunyai perencanaan dan melakukan proses evaluasi secara mandiri terhadap kegiatannya. Model lainnya adalah kemitraan terpadu yang bersifat lebih baik dan solid. Hal ini dikarenakan masing-masing anggota mitra memiliki tanggung jawab yang sama dalam mencapai tujuan.

Memiliki kehidupan yang sehat dan layak merupakan hak setiap warga negara. Bukan hanya kewajiban pemerintah untuk memelihara kesehatan setiap warganya, namun individu masyarakat juga harus berusaha agar tetap dapat menjaga dirinya dari segala ancaman penyakit dan masalah kesehatan lainnya. Dalam undang-undang kesehatan RI No. 36, tahun 2009, disebutkan bahwa setiap orang berkewajiban ikut mewujudkan, mempertahankan, dan meningkatkan derajat kesehatan masyarakat setinggi-tingginya. Sebagai upaya dalam hal ini, maka diperlukan adanya konsep pemberdayaan masyarakat sebagai salah satu strategi global dalam upaya mempromosikan kesehatan.

Notoatmodjo (2012), mengungkapkan bahwa pemberdayaan masyarakat merupakan suatu upaya atau proses untuk menumbuhkan kesadaran, kemauan, dan kemampuan masyarakat dalam mengenali, mengatasi, memelihara, melindungi, serta meningkatkan kesejateraannya sendiri. Dalam undang-undang kesehatan juga disinggung bahwa masyarakat dapat berperan serta, baik secara perorangan maupun terorganisasi dalam segala bentuk dan tahapan pembangunan kesehatan demi mempercepat tercapainya derajat kesehatan masyarakat setinggi-tingginya.

Pada prinsipnya pemberdayaan masyarakat dapat menumbuhkan peran serta dan kemampuan masyarakat untuk mengembangkan dirinya atau kelompok dengan bersumberdaya pada masyarakat itu sendiri. Oleh karena itu, perlu adanya peran provider sebagai fasilitator yang bekerja sama dengan masyarakat dalam rangka mewujudkan kemandirian masyarakat. Peran provider sebatas memberikan pengarahan, motivasi, dan mengadvokasi kegiatan yang dijalankan masyarakat. Sehingga provider bukan lagi bekerja untuk masyarakat, namun anggota masyarakat yang akan bekerja untuk masyarakat di wilayahnya.

\section{METODE}

Penelitian ini merupakan penelitian
observasional deskriptif dengan rancang bangun
cross sectional. Unit analisis penelitian adalah desa
di wilayah kerja Puskesmas Pamolokan. Sumber
informasi terdiri dari petugas Puskesmas yang
ditempatkan di desa yakni bidan desa dan
masyarakat yang terdiri dari perangkat desa, kader

Penelitian ini merupakan penelitian 
kesehatan, serta ibu bayi pada masing-masing desa. Pemilihan sampel dilakukan dengan menggunakan stratified random sampling.

Penelitian dilakukan pada sembilan desa di wilayah kerja Puskesmas Pamolokan, Kabupaten Sumenep, pada tanggal 19 September sampai 31 Oktober 2015. Lokasi desa yang digunakan sebagai subjek penelitian adalah Desa Pajagalan, Pangarangan, Pabian, Kacongan, Bangkal, Parsanga, Marengan Daya, Paberasan, dan Pamolokan. Teknik analisis penelitian dengan menggunakan analisis frekuensi dan regresi logistik untuk melihat gambaran pengaruh antar variabel.

\section{HASIL DAN PEMBAHASAN}

Salah satu faktor yang menyebabkan rendahnya cakupan desa UCI pada Puskesmas Pamolokan adalah belum optimalnya sistem kemitraan antara bidan desa sebagai petugas Puskesmas dengan perangkat desa dan kelompok masyarakat. Perangkat desa masih belum memperoleh laporan terkait program imunisasi, sehingga tidak dapat melakukan evaluasi terhadap masyarakatnya sendiri.

Menurut Notoatmodjo (2012), permasalahan kesehatan merupakan tanggung jawab bersama setiap individu, masyarakat, pemerintah, dan swasta. Dengan kata lain, untuk menyelesaikan permasalahan mengenai rendahnya cakupan desa $\mathrm{UCI}$, maka sektor kesehatan hendaknya menjalin kemitraan dengan berbagai sektor terkait khususnya yang terdapat di masyarakat.

Penelitian tentang kemitraan sebelumnya mengungkapkan bahwa kemitraan dipandang sebagai suatu kesisteman yang terdiri dari konsep input, process, dan output. Berdasarkan teori

Tabel 1 Identifikasi Peran Perangkat Desa dalam Sistem Kemitraan Desa di Wilayah Kerja Puskesmas Pamolokan

Variabel Peran Perangkat Desa

\begin{tabular}{|c|c|c|c|c|c|c|c|c|c|c|c|}
\hline \multirow[t]{2}{*}{ Nama Desa } & \multicolumn{2}{|c|}{$\begin{array}{c}\text { Pengetahua } \\
\mathbf{n}\end{array}$} & \multicolumn{2}{|c|}{$\begin{array}{c}\text { Akses } \\
\text { Informasi }\end{array}$} & \multicolumn{2}{|c|}{ Keterlibatan } & \multicolumn{2}{|c|}{$\begin{array}{c}\text { Pencatatan } \\
\text { dan } \\
\text { Pelaporan }\end{array}$} & \multirow[t]{2}{*}{$\begin{array}{l}\text { Total } \\
\text { Skor }\end{array}$} & \multirow[t]{2}{*}{ Kategori } & \multirow[t]{2}{*}{$\begin{array}{c}\text { Status } \\
\text { Desa }\end{array}$} \\
\hline & Skor & Kat. & Skor & Kat. & $\underset{r}{\text { Sko }}$ & Kat. & Skor & Kat. & & & \\
\hline Pajagalan & 100 & SB & 18 & $B$ & 15 & $\mathrm{~B}$ & 13 & $\mathrm{~B}$ & 146 & Baik & $\mathrm{UCl}$ \\
\hline Pangarangan & 100 & SB & 13 & $\mathrm{~B}$ & 11 & CB & 9 & CB & 133 & Baik & Non UCl \\
\hline Pabian & 71 & B & 18 & B & 9 & $\mathrm{CB}$ & 6 & $\mathrm{CB}$ & 104 & $\begin{array}{l}\text { Cukup } \\
\text { Baik }\end{array}$ & $\mathrm{UCl}$ \\
\hline Kacongan & 71 & $B$ & 21 & SB & 18 & $\mathrm{~B}$ & 15 & SB & 125 & Baik & $\mathrm{UCl}$ \\
\hline Bangkal & 86 & SB & 9 & CB & 8 & CB & 6 & $\mathrm{CB}$ & 109 & $\begin{array}{l}\text { Cukup } \\
\text { Baik }\end{array}$ & Non UCl \\
\hline Parsanga & 86 & SB & 14 & B & 9 & CB & 5 & $\mathrm{~K}$ & 114 & $\begin{array}{l}\text { Cukup } \\
\text { Baik }\end{array}$ & $\mathrm{UCI}$ \\
\hline $\begin{array}{l}\text { Marengan } \\
\text { Daya }\end{array}$ & 57 & $\mathrm{CB}$ & 12 & $\mathrm{CB}$ & 8 & $\mathrm{CB}$ & 7 & $\mathrm{CB}$ & 84 & Kurang & Non UCI \\
\hline Paberasan & 71 & $B$ & 10 & CB & 8 & CB & 7 & CB & 96 & Kurang & Non UCl \\
\hline Pamolokan & 100 & SB & 14 & $\mathrm{~B}$ & 15 & $B$ & 11 & $\mathrm{~B}$ & 140 & Baik & $\mathrm{UCl}$ \\
\hline
\end{tabular}

Keterangan: Kat $=$ Kategori, $\mathrm{SB}=$ Sangat Baik, $\mathrm{B}=$ Baik, $\mathrm{CB}=$ Cukup Baik, $\mathrm{K}=$ Kurang 
tersebut, maka dilaksanakanlah identifikasi input, process, dan output dari kemitraan dalam program imunisasi yang telah berjalan di wilayah kerja Puskesmas Pamolokan. Variabel input dalam penelitian ini terdiri dari perangkat desa, bidan desa sebagai petugas Puskesmas, serta kader kesehatan dan ibu bayi mewakili kelompok masyarakat.

Secara umum perangkat desa telah menjalankan perannya dengan baik. Tingkat pengetahuan perangkat desa sebagian besar sudah sangat baik, akses informasi dari Puskesmas terkait program imunisasi juga sudah diterima dengan baik. Namun keterlibatan perangkat desa untuk terjun langsung menangani program imunisasi di wilayah kerjanya masih perlu ditingkatkan.

Keterlibatan perangkat desa sebagian besar melakukan peninjauan dalam program Posyandu di wilayahnya. Sehingga kepala desa kurang mengetahui secara pasti mengenai sasaran, pihak yang terlibat, dan dana dalam program imunisasi. Demikian pula dengan sistem pencatatan dan pelaporan, kepala desa masih belum memiliki sistem pencatatan dan pelaporan secara khusus mengenai program imunisasi sehingga tidak dapat melakukan evaluasi imunisasi di wilayah kerjanya.

Dua dari sembilan kepala desa masih mendapatkan predikat kurang berperan dalam program imunisasi, sehingga berdampak pada hasil cakupan UCI desa yang masih dalam kategori nonUCI. Namun, terdapat dua desa lainnya yang masuk dalam kategori desa non-UCI yang kepala desanya telah berperan cukup baik, bahkan baik. Hasil analisis regresi logistik peran perangkat desa terhadap status desa dijabarkan dalam tabel 6 .

Mewakili provider Puskesmas Pamolokan yang di tugaskan di desa, peran bidan desa juga dirasa penting dalam menjalin kemitraan baik dengan perangkat desa ataupun masyarakat di wilayah kerjanya. Sebagian peran serta bidan desa di wilayah kerja Puskesmas Pamolokan sudah baik bahkan sangat baik. Hanya terdapat dua bidan desa yang perlu meningkatkan peran sertanya, terutama bidan desa yang wilayah kerjanya masih berstatus desa non-UCI.

Tabel 2 Identifikasi Peran Bidan Desa dalam Program Imunisasi di Desa Wilayah Kerja Puskemas Pamolokan

Variabel Peran Bidan Desa

\begin{tabular}{|c|c|c|c|c|c|c|c|c|c|c|c|}
\hline \multirow[t]{2}{*}{ Nama Desa } & \multicolumn{2}{|c|}{ Pengetahuan } & \multicolumn{2}{|c|}{ Keterlibatan } & \multicolumn{2}{|c|}{$\begin{array}{c}\text { Pencatatan } \\
\text { dan } \\
\text { Pelaporan }\end{array}$} & \multicolumn{2}{|c|}{$\begin{array}{c}\text { Pendekatan } \\
\text { ke } \\
\text { Masyarakat }\end{array}$} & \multirow[t]{2}{*}{$\begin{array}{l}\text { Total } \\
\text { Skor }\end{array}$} & \multirow[t]{2}{*}{ Kategori } & \multirow[t]{2}{*}{$\begin{array}{l}\text { Status } \\
\text { Desa }\end{array}$} \\
\hline & Skor & Kat. & Skor & Kat. & Skor & Kat. & Skor & Kat. & & & \\
\hline Pajagalan & 100 & SB & 22 & SB & 14 & $\mathrm{CB}$ & 22 & $\mathrm{~B}$ & 158 & SB & $\mathrm{UCl}$ \\
\hline Pangarangan & 100 & SB & 19 & SB & 11 & $\mathrm{CB}$ & 22 & $\mathrm{~B}$ & 152 & $\mathrm{~B}$ & Non UCl \\
\hline Pabian & 83 & $\mathrm{~B}$ & 19 & SB & 11 & $\mathrm{CB}$ & 23 & B & 136 & B & $\mathrm{UCI}$ \\
\hline Kacongan & 50 & $\mathrm{CB}$ & 19 & SB & 12 & $\mathrm{CB}$ & 23 & B & 104 & $\mathrm{CB}$ & $\mathrm{UCI}$ \\
\hline Bangkal & 100 & SB & 22 & SB & 13 & $\mathrm{CB}$ & 17 & $\mathrm{~B}$ & 152 & $B$ & Non UCl \\
\hline Parsanga & 100 & SB & 18 & $\mathrm{~B}$ & 11 & $\mathrm{CB}$ & 21 & $\mathrm{~B}$ & 150 & $\mathrm{~B}$ & $\mathrm{UCl}$ \\
\hline Marengan Daya & 100 & SB & 17 & B & 11 & CB & 17 & B & 145 & B & Non UCl \\
\hline Paberasan & 67 & CB & 19 & SB & 12 & $\mathrm{CB}$ & 18 & $\mathrm{~B}$ & 116 & CB & Non UCl \\
\hline Pamolokan & 83 & $B$ & 21 & SB & 14 & $\mathrm{CB}$ & 23 & B & 142 & $B$ & $\mathrm{UCI}$ \\
\hline
\end{tabular}

Keterangan: Kat $=$ Kategori, $\mathrm{SB}=$ Sangat Baik, $\mathrm{B}=$ Baik, $\mathrm{CB}=$ Cukup Baik, $\mathrm{K}=$ Kurang 
Tingkat pengetahuan bidan desa sebagian besar sudah sangat baik, demikian pula dengan keterlibatannya dalam program imunisasi. Namun perlu adanya perbaikan dari segi pencatatan dan pelaporan, hal ini dikarenakan pencatatan yang dilakukan bidan desa langsung dilaporkan kepada Puskesmas Pamolokan tanpa tembusan ke perangkat desa yang ada.

Perlu adanya tembusan sistem pelaporan kepada perangkat desa, agar perangkat desa memiliki catatan khusus terkait program imunisasi di wilayah kerjanya. Catatan ini dapat digunakan oleh perangkat desa sebagai bahan evaluasi terhadap program imunisasi yang telah berjalan di wilayah kerjanya.

Sebagian besar bidan desa sudah menjalankan kewenangannya dengan baik dalam melakukan pendekatan promotif ke masyarakat. Peran serta masyarakat di wilayah kerja Puskesmas Pamolokan sebagian besar sudah baik dengan tingkat persepsi masyarakat mengenai program imunisasi yang sangat baik. Keikutsertaan masyarakat perlu ditingkatkan, karena masyarakat masih melakukan imunisasi tidak sesuai dengan wilayah tinggalnya. Keterbukaan masyarakat juga dinilai kurang maksimal karena masyarakat tidak mengetahui adanya pihak yang terlibat dalam program imunisasi. Dalam hal dana masyarakat mengetahui adanya bantuan dana yang digunakan dalam program imunisasi, namun tidak mengetahui dana tersebut sudah digunakan sepenuhnya atau disubsidi dalam program kesehatan lainnya di wilayah Puskesmas Pamolokan. Variabel keterbukaan ini juga dinilai kurang sensitif dikarenakan masyarakat hanya mengetahui adanya dana untuk program imunisasi namun arah aliran dana tidak mengetahui secara pasti.

Tabel 3 Identifikasi Peran Masyarakat Desa dalam Program Imunisasi di Wilayah Kerja Puskesmas Pamolokan

Variabel Peran Masyarakat

\begin{tabular}{|c|c|c|c|c|c|c|c|c|c|c|c|}
\hline \multirow{3}{*}{ Nama Desa } & & \multirow{3}{*}{$\begin{array}{l}\text { Total } \\
\text { Skor }\end{array}$} & \multirow{3}{*}{ Kategori } & \multirow{3}{*}{$\begin{array}{c}\text { Status } \\
\text { Desa }\end{array}$} \\
\hline & \multicolumn{2}{|c|}{ Persepsi } & \multicolumn{2}{|c|}{ Keikutsertaan } & \multicolumn{2}{|c|}{ Keterbukaan } & \multicolumn{2}{|c|}{ Komitmen } & & & \\
\hline & Skor & Kat & Skor & Kat. & Skor & Kat. & $\begin{array}{c}\text { Sko } \\
r\end{array}$ & Kat. & & & \\
\hline Pajagalan & 11,22 & SB & 4,11 & CB & 6,78 & CB & $\begin{array}{r}5,0 \\
0 \\
\end{array}$ & CB & 27,11 & B & $\mathrm{UCl}$ \\
\hline Pangarangan & 11,67 & SB & 4,11 & CB & 7,11 & CB & $\begin{array}{r}4,7 \\
8 \\
\end{array}$ & CB & 27,67 & B & Non UCl \\
\hline Pabian & 11,44 & SB & 5,00 & CB & 7,78 & B & $\begin{array}{r}5,2 \\
2 \\
\end{array}$ & CB & 29,44 & B & $\mathrm{UCl}$ \\
\hline Kacongan & 11,67 & SB & 4,67 & CB & 7,67 & B & $\begin{array}{r}5,2 \\
2\end{array}$ & $\mathrm{CB}$ & 29,22 & $B$ & $\mathrm{UCl}$ \\
\hline Bangkal & 9,89 & B & 2,67 & $\mathrm{~K}$ & 5,44 & CB & $\begin{array}{r}4,3 \\
3 \\
\end{array}$ & $\mathrm{CB}$ & 22,33 & $\mathrm{CB}$ & Non UCI \\
\hline Parsanga & 11,33 & SB & 5,00 & CB & 6,89 & CB & $\begin{array}{r}4,7 \\
8\end{array}$ & CB & 28,00 & B & $\mathrm{UCl}$ \\
\hline $\begin{array}{l}\text { Marengan } \\
\text { Daya }\end{array}$ & 10,22 & $B$ & 2,78 & $\mathrm{~K}$ & 5,44 & CB & $\begin{array}{r}3,8 \\
9 \\
\end{array}$ & $\mathrm{~K}$ & 22,33 & CB & Non UCI \\
\hline Paberasan & 10,44 & $B$ & 2,89 & $\mathrm{~K}$ & 5,89 & CB & $\begin{array}{r}4,3 \\
3 \\
\end{array}$ & CB & 23,56 & CB & Non UCI \\
\hline Pamolokan & 11,56 & SB & 4,89 & CB & 7,89 & B & $\begin{array}{r}5,1 \\
1 \\
\end{array}$ & CB & 29,44 & B & $\mathrm{UCl}$ \\
\hline
\end{tabular}

Keterangan: Kat $=$ Kategori, $\mathrm{SB}=$ Sangat Baik, $\mathrm{B}=$ Baik, $\mathrm{CB}=$ Cukup Baik, $\mathrm{K}=$ Kurang 
Tabel 4 Identifikasi Proses Kemitraan Berbasis Masyarakat yang Telah Berjalan di Wilayah Kerja Puskesmas Pamolokan

\begin{tabular}{|c|c|c|c|c|c|c|c|c|c|c|c|c|c|c|c|}
\hline \multirow{3}{*}{$\begin{array}{l}\text { Nama } \\
\text { Desa }\end{array}$} & \multicolumn{12}{|c|}{ Variabel Peran Masyarakat } & \multirow{3}{*}{$\Sigma$} & \multirow{3}{*}{ Kat. } & \multirow{3}{*}{$\begin{array}{c}\text { Statu } \\
\mathbf{s} \\
\text { Desa }\end{array}$} \\
\hline & $\begin{array}{c}\text { Penjajag } \\
\text { an/ } \\
\text { Komunik } \\
\text { asi }\end{array}$ & $\begin{array}{c}\text { Penyam } \\
\text { a-an } \\
\text { Persep } \\
\text { si }\end{array}$ & \multicolumn{2}{|c|}{$\begin{array}{c}\text { Peengat } \\
\text { ur-an } \\
\text { Peran }\end{array}$} & \multicolumn{2}{|c|}{$\begin{array}{c}\text { Kesepak } \\
\text { at-an } \\
\text { Bermitra }\end{array}$} & \multicolumn{2}{|c|}{$\begin{array}{c}\text { Menyusu } \\
\mathbf{n} \\
\text { Rencana } \\
\text { Bersama }\end{array}$} & \multicolumn{2}{|c|}{$\begin{array}{c}\text { Melaksa } \\
\text { na-kan } \\
\text { Kegitan }\end{array}$} & \multicolumn{2}{|c|}{$\begin{array}{c}\text { Monitori } \\
\text { ng dan } \\
\text { Evaluasi }\end{array}$} & & & \\
\hline & $\begin{array}{cc}\text { Sko } & \text { Kat } \\
\mathbf{r} & \text {. }\end{array}$ & $\begin{array}{cc}\text { Sk } & \text { Kat } \\
\text { or } & \text {. }\end{array}$ & $\begin{array}{l}\text { Sk } \\
\text { or }\end{array}$ & $\begin{array}{c}\text { Kat } \\
.\end{array}$ & $\begin{array}{l}\text { Sk } \\
\text { or }\end{array}$ & $\begin{array}{c}\text { Kat } \\
.\end{array}$ & Skor & $\begin{array}{c}\text { Kat } \\
.\end{array}$ & $\begin{array}{c}\text { Sko } \\
r\end{array}$ & $\begin{array}{c}\mathrm{Ka} \\
\mathrm{t} .\end{array}$ & $\begin{array}{c}\text { Sko } \\
r\end{array}$ & $\begin{array}{c}\mathrm{Ka} \\
\mathrm{t.}\end{array}$ & & & \\
\hline Pajagalan & $18,45 \mathrm{SB}$ & $\begin{array}{r}13,0 \\
0\end{array}$ SB & $\begin{array}{r}17,6 \\
4 \\
\end{array}$ & $B$ & $\begin{array}{r}8,8 \\
2 \\
\end{array}$ & SB & 12,91 & B & $\begin{array}{r}15,8 \\
2 \\
\end{array}$ & $\mathrm{~B}$ & 10,36 & SB & $\begin{array}{r}27,1 \\
1 \\
\end{array}$ & B & $\mathrm{UCl}$ \\
\hline $\begin{array}{l}\text { Pangarang } \\
\text { an }\end{array}$ & 16,73 B & $\begin{array}{r}12,6 \\
4\end{array}$ & $\begin{array}{r}16,1 \\
8 \\
\end{array}$ & B & $\begin{array}{r}7,7 \\
3\end{array}$ & B & 12,00 & $B$ & $\begin{array}{r}15,6 \\
4 \\
\end{array}$ & B & 9,27 & B & $\begin{array}{r}27,6 \\
7\end{array}$ & B & $\begin{array}{l}\text { Non } \\
\text { UCl }\end{array}$ \\
\hline Pabian & $18,27 \mathrm{SB}$ & $\begin{array}{r}13,0 \\
0\end{array}$ & $\begin{array}{r}17,9 \\
1 \\
\end{array}$ & B & $\begin{array}{r}9,0 \\
0\end{array}$ & SB & 13,27 & SB & $\begin{array}{r}16,0 \\
0 \\
\end{array}$ & B & 10,82 & SB & $\begin{array}{r}29,4 \\
4 \\
\end{array}$ & B & $\mathrm{UCl}$ \\
\hline Kacongan & $18,91 \mathrm{SB}$ & $\begin{array}{r}12,8 \\
2\end{array}$ & $\begin{array}{r}16,8 \\
2 \\
\end{array}$ & $B$ & $\begin{array}{r}8,6 \\
4 \\
\end{array}$ & SB & 13,27 & SB & $\begin{array}{r}15,8 \\
2 \\
\end{array}$ & B & 10,55 & SB & $\begin{array}{r}29,2 \\
2 \\
\end{array}$ & $\mathrm{~B}$ & $\mathrm{UCl}$ \\
\hline Bangkal & $10,73 \mathrm{CB}$ & $\begin{array}{r}12,1 \\
8\end{array}$ & $\begin{array}{r}12,9 \\
1 \\
\end{array}$ & CB & $\begin{array}{r}6,3 \\
6 \\
\end{array}$ & CB & 7,36 & CB & 9,91 & CB & 5,55 & CB & $\begin{array}{r}22,3 \\
3 \\
\end{array}$ & $\mathrm{CB}$ & $\begin{array}{l}\text { Non } \\
\text { UCl }\end{array}$ \\
\hline Parsanga & $18,27 \mathrm{SB}$ & $\begin{array}{r}13,0 \\
0\end{array}$ SB & $\begin{array}{r}18,0 \\
0 \\
\end{array}$ & SB & $\begin{array}{r}8,8 \\
2 \\
\end{array}$ & SB & 13,00 & SB & $\begin{array}{r}16,0 \\
9 \\
\end{array}$ & $B$ & 10,73 & SB & $\begin{array}{r}28,0 \\
0 \\
\end{array}$ & B & $\mathrm{UCI}$ \\
\hline $\begin{array}{l}\text { Marengan } \\
\text { Daya }\end{array}$ & $11,36 \mathrm{CB}$ & $\begin{array}{r}12,1 \\
8\end{array}$ & $\begin{array}{r}13,3 \\
6 \\
\end{array}$ & CB & $\begin{array}{r}6,4 \\
5\end{array}$ & CB & 7,64 & CB & $\begin{array}{r}10,3 \\
6 \\
\end{array}$ & CB & 6,00 & CB & $\begin{array}{r}22,3 \\
3 \\
\end{array}$ & CB & $\begin{array}{l}\text { Non } \\
\text { UCI }\end{array}$ \\
\hline Paberasan & $16,36 \mathrm{~B}$ & $\begin{array}{r}12,1 \\
8\end{array}$ & $\begin{array}{r}15,5 \\
-\quad 5 \\
\end{array}$ & B & $\begin{array}{r}7,5 \\
5 \\
\end{array}$ & B & 11,55 & $B$ & $\begin{array}{r}14,9 \\
1 \\
\end{array}$ & B & 8,64 & B & $\begin{array}{r}23,5 \\
6 \\
\end{array}$ & CB & $\begin{array}{l}\text { Non } \\
\text { UCl }\end{array}$ \\
\hline $\begin{array}{l}\text { Pamoloka } \\
\mathrm{n}\end{array}$ & $18,55 \mathrm{SB}$ & $\begin{array}{r}13,0 \\
0\end{array}$ SB & $\begin{array}{r}18,0 \\
9 \\
\end{array}$ & SB & $\begin{array}{r}9,0 \\
0\end{array}$ & SB & 13,36 & SB & $\begin{array}{r}16,2 \\
7 \\
\end{array}$ & B & 10,82 & SB & $\begin{array}{r}29,4 \\
4 \\
\end{array}$ & $B$ & $\mathrm{UCl}$ \\
\hline
\end{tabular}

Keterangan: Kat $=$ Kategori, $\mathrm{SB}=$ Sangat Baik, B $=$ Baik, CB $=$ Cukup Baik, $\mathrm{K}=$ Kurang

Komitmen masyarakat termasuk dalam kategori cukup baik. Masyarakat telah bersedia untuk turut serta dalam menyukseskan program imunisasi di wilayahnya. Namun, dikarenakan keterbatasan waktu ibu bayi yang bekerja, maka ibu bayi belum dapat mengajak ibu lainnya untuk melakukan imunisasi sesuai dengan wilayah tinggalnya. Hasil analisis regresi logistik peran masyarakat terhadap hasil cakupan desa UCI dijabarkan dalam Tabel 6.

Beberapa dimensi input yang telah dijabarkan bukan serta merta faktor yang dapat mempengaruhi hasil cakupan desa UCI. Diperlukan adanya proses lebih lanjut yang berjalan secara sistematis untuk menggerakkan ketiga dimensi input tersebut. Proses kemitraan di wilayah kerja Puskesmas Pamolokan sebagian besar masuk dalam kategori baik, namun masih ada tiga desa yang masih ada dalam kategori cukup baik dan status desanya juga masih belum berhasil mencapai desa UCI.

Proses penjajagan/komunikasi baik dari bidan desa ke perangkat desa, ataupun dari perangkat desa dan bidan desa ke masyarakat sebagian besar sudah baik bahkan sangat baik. Penyamaan persepsi di masyarakat terkait program imunisasi sebahian besar juga sudah baik. Pengaturan peran juga sudah baik, perangkat desa, bidan desa, hingga kader kesehatan telah menjalankan tugas sesuai dengan fungsinya. Kesepakatan untuk bermitra dalam rangka meningkatkan program imunisasi juga sudah baik, meskipun tidak ada kesepakatan secara tertulis antara perangkat desa dengan pihak Puskesmas.

Perencanaan terkait program imunisasi pada beberapa desa telah disusun secara gotong royong. Namun beberapa perlu adanya pembenahan, 
Tabel 5 Identifikasi Hasil Kemitraan Berbasis Masyarakat di Wilayah Kerja Puskesmas Pamolokan

\begin{tabular}{|c|c|c|}
\hline \multirow{3}{*}{ Nama Desa } & Hasil Kemitraan & \multirow{3}{*}{ Status Desa } \\
\hline & Sinergisme & \\
\hline & Kategori & \\
\hline Pajagalan & 12,64 Baik & $\mathrm{UCl}$ \\
\hline Pangarangan & 12,36 Baik & Non UCl \\
\hline Pabian & 13,55 Sangat Baik & $\mathrm{UCl}$ \\
\hline Kacongan & 11,27 Baik & $\mathrm{UCl}$ \\
\hline Bangkal & 9,91 Cukup Baik & Non UCI \\
\hline Parsangan & 12,64 Baik & $\mathrm{UCl}$ \\
\hline Marengan Daya & 9,09 Cukup Baik & Non UCI \\
\hline Paberasan & 9,73 Cukup Baik & Non UCl \\
\hline Pamolokan & 13,00 Sangat Baik & $\mathrm{UCl}$ \\
\hline
\end{tabular}

mengingat dengan melakukan perencanaan secara bersama-sama masyarakat merasa terlibat aktif untuk menyukseskan program imunisasi ini. Kegiatan imunisasi sudah dijalankan secara bersamaan baik melalui program posyandu, ataupun di polindes yang tersebar di beberapa desa.

Proses monitoring dan evaluasi juga telah dilakukan dengan baik, namun perlu adanya pembenahan proses monitoring dan evaluasi di tingkat desa agar kepala desa dapat turut serta mengajak warganya untuk diberikan imunisasi. Mengenai hasil analisis regresi logistik antara proses kemitraan terhadap hasil cakupan desa UCI akan dijabarkan dalam Tabel 6.

Dengan aspek input dan process sistem kemitraan yang baik, diharapkan diikuti dengan hasil yang baik untuk mencapai hasil cakupan desa UCI sesuai dengan target yang di tetapkan pemerintah. Hasil dari sistem kemitraan yang akan diidentifikasi adalah sinergisme dari program imunisasi yang telah dijalankan selama ini.

Sebagian besar masyarakat telah bersinergi baik dengan perangkat desa dan bidan desa ataupun sebaliknya. Hanya ada tiga desa yang perlu meningkatkan sinergismenya. Hal ini berpengaruh terhadap hasil cakupan desa yang masih dalam status non-UCI. Hasil analisis regresi logistik antara variabel input, process, dan output dengan menganalisi peran serta perangkat desa, bidan desa, dan kelompok masyarakat terhadap hasil cakupan desa UCI dijabarkan dalam tabel 6.

Tidak ada pengaruh yang signifikan antara variabel peran perangkat desa dan bidan desa terhadap hasil cakupan desa UCI. Hal ini dikarenakan, karakteristik perangkat desa dan bidan desa di wilayah kerja Puskesmas Pamolokan secara keseluruhan hampir sama. Perangkat desa dan bidan desa telah menjalankan tugasnya sesuai dengan fungsi dan kewenangan yang telah ditetapkan pemerintah.

Sistem pencatatan dan pelaporan pada seluruh desa di wilayah kerja Puskesmas Pamolokan secara keseluruhan sama. Hasil pencatatan program imunisasi yang telah dilakukan bidan desa dilaporkan secara langsung kepada Puskesmas Pamolokan. Sehingga perangkat desa tidak mengetahui sasaran hingga cakupan proses imunisasi yang akan dijalankan. 
Dalam tabel 6 dijabarkan bahwa terdapat terdapat dua variabel peran masyarakat yang memiliki pengaruh signifikan terhadap hasil cakupan desa UCI. Variabel penyamaan persepsi dan keikutsertaan masyarakat adalah variabel yang memiliki pengaruh signifikan terhadap hasil cakupan desa UCI yaitu variabel penyamaan persepsi dan keikutsertaan. Hal ini sesuai dengan penelitian sebelumnya yang menyatakan bahwa keikutsertaan masyarakat merupakan cara yang efektif membangun kemampuan masyarakat untuk

Tabel 6 Hasil Analisis Regresi Logistik pengelolaan program pembangunan (Muslim, 2007). Dengan nilai signifikansi 1,632, dapat disimpulkan bahwa dengan persepsi masyarakat yang baik terkait program imunisasi desa akan meraih status desa UCI 1,632 kali lebih baik jika dibandingkan dengan desa yang masyarakatnya memiliki persepsi yang kurang baik terkait program imunisasi. Oleh karenanya perlu adanya penyampaian informasi yang menyeluruh kepada masyarakat agar persepsi masyarakat terhadap program imunisasi semakin baik.

Variabel

Hasil Analisis

Sig. $\quad \operatorname{Exp}(B)$

\section{Peran Perangkat Desa}

\begin{tabular}{lcc}
\hline Informasi & 1,000 & $5,602 \mathrm{E} 17$ \\
\hline Keterlibatan & 1,000 &, 000 \\
\hline Pencatatan dan Pelaporan & 1,000 & $8,777 \mathrm{E} 90$ \\
\hline Pengetahuan & 1,000 & $1,206 \mathrm{E} 20$ \\
\hline
\end{tabular}

\section{Peran Bidan Desa}

\begin{tabular}{lcc}
\hline Pengetahuan &, 304 & 1,867 \\
\hline Keterlibatan &, 855 & 1,195 \\
\hline Pencatatan dan Pelaporan &, 479 &, 479 \\
\hline Pendekatan Ke Masyarakat &, 840 & 1,054 \\
\hline
\end{tabular}

\section{Peran Masyarakat}

\begin{tabular}{llcc}
\hline Persepsi &, 007 & 1,632 \\
\hline Keikutsertaan &, 000 &, 296 \\
\hline Keterbukaan &, 631 & 1,117 \\
\hline Komitmen &, 313 &, 695 \\
\hline Komunikasi &, 024 &, 640 \\
\hline
\end{tabular}

\section{Proses Kemitraan}

\begin{tabular}{lcc}
\hline Penyamaan Persepsi &, 000 & 3,610 \\
\hline Pengaturan Peran &, 970 &, 992 \\
\hline Kesepakatan Bermitra &, 629 &, 836 \\
\hline Menyusun Rencana Bersama &, 953 & 1,012 \\
\hline Melaksanakan Kegiatan &, 112 & 1,432 \\
\hline Monitoring dan Evaluasi &, 000 &, 259 \\
\hline
\end{tabular}

\section{Hasil Kemitraan}


Tabel 6 juga menjabarkan bahwa terdapat tiga dari tujuh variabel proses kemitraan yang memiliki pengaruh signifikan terhadap hasil cakupan desa UCI. Komunikasi merupakan salah satu variabel yang berpengaruh signifikan terhadap hasi cakupan desa UCI. Hal ini sesuai dengan penelitian sebelumnya yang mengungkapkan bahwa komunikasi dapat mewarnai keberhasilan kerjasama (Triwilopo, 2013). Saat petugas kesehatan secara strategis melakukan komunikasi dengan para stakeholder ataupun pihak yang bermitra maka akan mempengaruhi persepsi pihak yang bermitra.

Dengan nilai signifikasi lebih dari tiga, dapat disimpulkan bahwa dengan melakukan penyamaan persepsi di masyarakat, maka status UCI desa akan mudah didapat 3,610 kali lebih baik, jika dibandingkan dengan masyarakat yang persepsinya tidak sama satu dengan yang lainnya. Dengan terciptanya persepsi yang sama, pihak yang bermitra akan membangun gambaran mereka sendiri tentang program yang harus dijalankannya. Hal ini sesuai dengan hasil dalam penelitian yang juga mengungkapkan bahwa penyamaan persepsi memiliki pengaruh yang signifikan terhadap hasil cakupan desa UCI.

Bukan hanya melakukan penyamaan persepsi dan melaksanakan kegiatan yang diawali dengan melakukan perencanaan bersama dengan mitra kerja memiliki pengaruh yang signifikan terhadap status desa UCl sebesar 1,012 kali. Melakukan proses monitoring dan evaluasi secara terpadu juga akan berpengaruh terhadap status desa UCI sebesar 0,259 kali lebih baik.
Berdasarkan tabel 6, dapat diketahui bahwa terdapat pengaruh yang signifikan antara variabel sinergisme terhadap hasil cakupan desa $\mathrm{UCI}$. Dengan melihat nilai signifikansi dari variabel sinergisme, dapat diartikan bahwa masyarakat yang memiliki tingkat sinergisme yang baik dalam program imunisasi akan berpotensi 0,675 kali mencapai target cakupan desa $\mathrm{UCI}$, dibandingkan dengan desa yang memiliki tingkat sinergisme yang kurang baik.

\section{SIMPULAN}

Secara keseluruhan sistem kemitraan berbasis masyarakat di wilayah kerja Puskesmas Pamolokan belum optimal pada beberapa desa. Masyarakat desa di wilayah kerja Puskesmas Pamolokan sebagian besar menggunakan model sistem kemitraan jejaring kerja (networking) dengan melakukan perencanaan, pelaksanaan, hingga proses evaluasi secara mandiri.

Berdasarkan hasil identifikasi input, process, dan output perlu adanya peningkatan sistem kemitraan yang efektif dan efisien, khususnya pada Desa Bangkal, Marengan Daya, dan Paberasan. Untuk menciptakan sistem kemitraan yang efektif dan efisien diperlukan sistem kemitraan yang terpadu dan lebih solid.

Hampir seluruh bidan desa tidak melakukan pelaporan kepada kepala desa, melainkan langsung melakukan pelaporan ke Puskesmas Pamolokan. Hal ini mengakibatkan perangkat desa tidak memiliki sistem pencatatan terkait program imunisasi. Sehingga akan mempengaruhi kinerja perangkat desa dalam menjalin mitra di masyarakat. 
Dengan tidak adanya sistem pencatatan dan pelaporan di tingkat desa, perangkat desa tidak akan dapat melakukan proses monitoring dan evaluasi terhadap hasil cakupan desa UCI.

Berdasarkan hasil analisis proses kemitraan, hampir seluruh desa belum mempunyai kesepakatan secara tertulis dengan pihak Puskesmas Pamolokan. Kesepakatan tertulis ini diperlukan guna menambah motivasi kepada masyarakat agar membawa anaknya untuk diimunisasi secara sadar dan sukarela.

Perlu adanya kebijakan dari pihak Puskesmas Pamolokan atau Dinas terkait untuk membuat komitmen atau kesepakatan secara tertulis dengan perangkat desa dalam rangka mendukung tercapainya target $100 \%$ desa UCI pada masingmasing wilayah desa. Dengan adanya kesepakatan tertulis yang terjalin antara perangkat desa dan pihak Puskesmas, maka masyarakat akan semakin termotivasi untuk memberikan imunisasi kepada bayinya.

\section{DAFTAR PUSTAKA}

Menteri Kesehatan Republik Indonesia (2004). Keputusan Menteri Kesehatan Nomor 128/MENKES/SK/II/2004 tentang Kebijakan Dasar Pusat Kesehatan Masyarakat (Puskesmas). Jakarta: Kementerian Kesehatan Republik Indonesia.

Menteri Kesehatan Republik Indonesia. (2004). Keputusan Menteri Kesehatan Republik Indonesia Nomor 1059/MENKES/SK/IX/2004 tentang Pedoman Penyelenggaraan Imunisasi. Jakarta: Kementerian Kesehatan Republik Indonesia.

Muslim, Aziz. (2007). Pendekatan Partisipatif Dalam Pemberdayaan Masyarakat. Jurnal Aplikasi Ilmu-ilmu Agama. Aplikasia, 8: 89-103.

Notoatmodjo, Sukidjo. (2012). Promosi Kesehatan dan Perilaku Kesehatan. Surabaya: Rianeka Cipta.

Pramudho, P.A.K.. (2009). Pengembangan Instrumen Pengukuran Kemitraan Desa Siaga di Kabupaten Subang, Jawa Barat. Tesis. Depok: Universitas Indonesia.

Presiden Republik Indonesia. (2009). Undang Undang Kesehatan Republik Indonesia Nomor 36 Tahun 2009. Jakarta: Kementerian Hukum dan HAM Republik Indonesia.

Triwilopo, Sendi. (2013). Pengaruh Strategi Kemitraan Terhadap Citra Perusahaan. Program Magister IImu Komunikasi Universitas Padjadjaran 